\title{
A CONSTRUÇÃO DE UM MUNICÍPIO SAUDÁVEL: DESCENTRALIZAÇÃO E INTERSETORIALIDADE - EXPERIÊNCIA DE FORTALEZA
}

\author{
Regina Celia Ribeiro *
}

\begin{abstract}
Resumo: Neste trabalho são relatadas as experiências do Município de Fortaleza na busca da resolutividade para os problemas de saúde da população, desde o processo de municipalização ocorrido em 1990, até a mudança organizacional iniciada em 1997. A descentralização e a intersetorialidade são destacadas como fundamentais na construção de um novo modelo que visa à "saúde como melhoria de qualidade de vida" rumo a um Municipio Saudável.
\end{abstract}

Palavras-chave: Descentralização, Intersetorialidade, Qualidade de Vida, Municipio Saudável

* Médica, Coordenadora de Saúde da Secretaria Municipal de Desenvolvimento Social de Fortaleza 


\section{ATENCEDENTES}

Os pressupostos nos quais o conceito de "Municípios/Cidades Saudáveis" se baseiam não são desconhecidos ou novos para os diversos atores envolvidos no processo de resolução dos problemas de saúde da população de Fortaleza, primeira cidade do Brasil a municipalizar suas ações e serviços de saúde em 1990, bem antes da IX Conferência Nacional de Saúde cujo tema central "Saúde: Municipalização é o Caminho" enfocava "Saúde como Qualidade de Vida" em 1992. Muitos foram os caminhos buscados para a efetiva descentralização num processo de transformação que envolveu redistribuição de poder e recursos, redefinição de papéis, reformulação de práticas e estabelecimento de novas relações - profissionais $\mathrm{X}$ usuários $\mathrm{e}$ implantação dos Conselhos de Saúde (Local, Distrital e Municipal).

\section{ADISTRITALIZAÇÃO}

O processo de implantação dos Distritos Sanitários em Fortaleza iniciado em 1983 foi oficializado em 1990 passando a compor a estrutura administrativa da Secretaria de Saúde em número de 9 (nove), coincidiṇdo com as Regiöes Administrativas do municipio, buscando já naquele tempo viabilizar a Intersertorialidade das ações de saúde, estratégia considerada inovadora e difíill de ser efetivada sobretudo pela cultura organizacional Setorial e centralizadora das Secretarias.

Em 1991 com o apoio da Organização Panamericana de Saúde (OPS) desencadeouse um programa de consultoria no Distrito Sanitário V (José Walter) com oficinas de territorialização e de Sistema de Informação que possibilitou o reconhecimento do território, o levantamento e sistematização de informação e a reorganização de alguns serviços, inclusive com remanejamento de pessoal.

\section{O PROJETO SMALP}

Em janeiro de1993 o apoio da OPS através do Projeto SMALP (Saúde, Meio Ambientee Luta Contra a Pobreza) proporcionou avanços significativos no processo de distritalização com oficinas de territorialização em todos os Distritos Sanitários expandindo assim a experiência iniciada no Distrito Sanitário V. Oficinas de capacitação para conselheiros possibilitaram a reestruturação e implementação dos Conselhos de Saúde fortalecendo o controle social. 


\section{O PROJETO GERUS}

A capacitação dos Gerentes de Unidades Básicas de Saúde através do Projeto Gerus realizado em parceria com o Programa de Desenvolvimento de Recursos Humanos-OPAS, Universidade Federal do Ceará através do Núcleo de Estudos em Saúde Coletiva (NESC) e Projeto Smalp deu subsidios para a realização do planejamento e programação em todas as Unidades Básicas de Saúde redirecionando as práticas de trabalho numa atuação voltada para a "Vigilância à Saúde".

\section{SEMINÁRIO: “ALTERNATIVAS DE RENDA PARA O USUÁRIO DO SUS”}

Ainda em 93 (Julho) foi realizado o Seminário "Alternativas de Renda para o Usuário do SUS"com a participação de Instituições Municipais, Organizações Nacionais, Internacionais, Associaçōes Comunitárias, Conselheiros onde foram discutidos problemas identificados nas oficinas de territorialização que extrapolavam a área de governabilidade do "setor saúde".

Como proposta deste Seminário ficou acordado que os problemas identificados nas aréas seriam trabalhados com outras Secretarias com a participação efetiva dos Conselhos Distritais de Saúde.

Este momento serviu sobretudo para a constatação da necessidade de um Planejamento Participativo e voltado para o enfrentamento de probelmas identificados pelo Nivel Local e a busca de soluções Intersetoriais. O Plano Operativo Anual e o orçamento/94 foram ajustados à partir dos Planos de Ações das Unidades. Apesar dos avanços conseguidos na implantação de um novo modelo assistencial voltado para a Vigilância à Saúde as epidemias de Cólera, Dengue e Meningite embora amplamente anunciadas não conseguiram ser evitadas, demonstrando claramente que "os esforços para melhorar a saúde da população serão inúteis se não forem acompanhados de ações para eliminar a pobreza e preservar o meio ambiente." (OPAS, série HSS/SILOS, $n^{\circ}$ 27)

\section{O PROGRAMA DE AGENTES COMUNITÁRIOS DE SAÚDE (PACS)}

Em 1994 o Programa de Agentes Comunitários de Saúde (PACS) é reestruturado contando com 1.000 agentes cada um responsável pelo acompanhamento de 300 familias, em média localizadas nas áreas de risco. O Sistema de Informação do PACS possibilitou a construção da Taxa de Mortalidade Infantil Mensal permitindo uma intervenção precoce e a inversão do fluxo 
da informação provocou uma reorganização dos serviços baseada até então exclusivamente na demanda espontânea e programas verticalizados.

O Cadastramento de todas as familias das áreas de risco, identificando, registrando e acompanhando todas as gestantes e crianças de 0 a 23 meses permitiu o monitoramento de indicadores de Vigilância à Saúde (entre outros).

$\%$ gestantes com pré-natal-em dia

$\%$ de crianças de 0 a 4 meses com aleitamento materno exclusivo.

$\%$ de crianças de 0 a 11 meses com vacinas em dia.

\section{PROJETO DE REDUÇÃO DA MORTALIDADE INFANTIL}

A Construção da Taxa de Mortalidade Infantil alta (28/1000) nos obrigou a elaboração de um Projeto de redução da Montalidade Infantil tendo como estratégias o Monitoramento de Nascidos Vivos de Risco através de visitas semanais às maternidades realizados pelas InstrutorasSupervisoras do PACS e Monitoramento de Óbitos em menores de 1 ano mensalmente em todos os cemitérios com posterior investigação da causa dos óbitos através de visita domiciliar (Autopsia Verbal).

A Taxa de Mortalidade Infantil por Bairro foi construida identificando assim as áreas de maiores riscos por causas de óbitós. $A$ análise destes dados coincidiu com as áreas de mais baixos indicadores sociais e econômicos indicando com muita clareza da necessidade de politicas sociais e econômicas que combatessem a Fome, a Miséria, as condições inadequadas de moradia, o Analfabetismo e o Saneamento Básico para a construção de um Município Saudável com projetos e programas direcionados para a Melhoria da Qualidade de Vida.

\section{SAÚDE COMO QUALIDADE DE VIDA}

A necessidade do compromisso com a melhoria da qualidade de vida como condição básica para viabilizar a produção de uma sociedade saudável e não reprodutora de doenças foi discutida no I Congresso de Secretários Municipais de Saúde das Américas em Fortaleza/Out/ 95. O enfoque de saúde como Processo e Produto Social com ênfase na Intersetoriedade e Descentralização foi estimulado (Carta de Fortaleza, 1995). 
Em junho de 97 no II Congresso de Secretarias Municipais de Saúde das Américas/ Havana a proposta é de fortalecimento de uma nova agenda que privilegie a "Saúde como Qualidade de Vida", construção do paradigma da Saúde a partir do conceito social da Saúde, Intersetorialidade e Participação Popular. (Carta de La Habana, 1997) A formação de Redes Nacionais de Municípios Saudáveis é estimulada. É neste contexto que Fortaleza inicia seu processo de mudança organizacional.

\section{A NECESSIDADE DA MUDANÇA}

Segundo CAMPOS (1994) temos que mexer, simultaneamente, com as pessoas, com as estruturas e com as relações entre elas se almejamos obter sucesso em qualquer projeto mudancista. A mudança de estrutura pode determinar uma nova maneira de gerenciar mas não sua eficácia comenta Junqueira (5) com relação a experiência de Fortaleza.

A busca da melhoria de qualidade de vida da população exigia ações integradas e articuladas que as politicas setoriais isoladas não apresentavam resolutividade. A proposta de um novo modelo Descentralizado e Intersetorial se consolidou com um novo prefeito Dr. Juraci Magalhães e uma nova Lei, a $n^{\circ} 8.000$ de 25 de janeiro de 1997. A construção do novo implica em perda e redistribuição de poder e mudança de hábitos antigos e arraigados o que exigiu vários seminários com funcionários para discussão e ganho de adeptos e parceiros.

\section{ANOVA ORGANIZAÇÃO ADMINISTRATIVA}

A Prefeitura Municipal de Fortaleza passa a se organizar com os seguintes objetivos:

Garantir o acesso do cidadãj aos serviços, às informações e participação nas decisões referentes ao espaço urbano onde ele vive e atua.

Ampliar a efetividade das ações realizadas pelo Governo Municipal e a reponsabilização de seus agentes, mediante transparência, moralidade e descentralização da Gestão Municipal.

É o governo chegando próximo ao cidadão, identificando seus problemas e dando soluções integradas.

As Secretarias Executivas Regionais (SER) foram criadas em número de 6(seis) com a responsabilidade pelo atendimento da popılação em suas respectivas áreas de abrangência 
proporcionado condições para a Melhoria de Qualidade de Vida e desenvolvimento de espaços de convivência saudáveis através de programas integrados de emprego e renda e garantia do acesso aos serviços de saúde, educação, assistência social, cultura, lazer e esporte.

A extinção das Secretarias de Educação, Saúde e Trabalho e Ação Social do municipio foi um ato de coragem e ousadia que mexeu profundamente com a vida dos servidores. Segundo CAMPOS (1994) as coisas e as pessoas são duras à mudanças. A resistência ao remanejamento de servidores destas áreas para as Secretarias Regionais não ocorreram sem traumas...

A Secretaria de Desenvolvimento Social (SMDS) foi criada com o objetivo de integrar as politicas sociais no macro-espaço, planejando, monitorando indicadores, definindo prioridades para o grupo de crianças, adolescentes, famílias e trabalhadores do municipio. É Articuladora, não executiva. A constituição de coordenadorias de Saúde, Educação, Habitação e Trabalho permite assessoramento técnico às Secretarias Executivas Regionais e o "sentar junto" para resoluçắo dos problemas é um exercício contínuo mas ainda novo e construido a cada dia de intersetorialidade.

A Secretaria de Desenvolvimento Territorial (SMDT) éa responsável pelo planejamento e articulação intersetorial das politicas de controle urbano, meio ambiente, transportes, obras viárias, obras municipais e limpeza urbana. Controla e Articula as ações realizadas pelos SER.

Todas as ações que ultrapassem o âmbito de uma regional exigem a intervenção da SMDS ou SMDT.

\section{CONCLUSÃO}

Fortaleza vivencia um Processo de Mudança baseado na lógica da Descentralização, Intersetorialidade e Participação Popular, buscando a Melhoria da Qualidade de Vida da população, transformando a cidade em um espaço de produção social da saúde em que todas as pessoas tenham satisfeitos suas necessidades básicas: educação, saúde, habitação, água, renda, segurança, trabalho.

Durante algum tempo imaginamos que este processo poderia ser conduzido pela Secretaria de Saúde, hoje acreditamos que só a condução a nivel do Prefeito pode garantir a descentralização (e não desconcentração) e a intersetorialidade. 
Na prática apesar da decisão política, a intersetorialidade não ocorre automaticamente, é um exercício de construção diária com avanços e retrocessos.

O Planejamento Plurianual realizado com a participação da Comunidade através de várias reuniões nos SER's foi um exercicio de prática intersetorial e participação popular.

Estamos apenas no inicio do processo rumo ao Município Saudável e solidário cujo compromisso é sobretudo com a equidade!

\section{REFERÊNCIAS BIBLIOGRÁFICAS}

PROYECTO SALUD Medio Ambiente y Lucha contra da Pobreza. Washington, D.C., OPAS, serie HSS/SILOS N²7,P.93.

CARTA de Fortaleza [Texto apresentado ao I Congresso de Secretários Municipais de Saúde das Américas, Fortaleza, 13 de Outubro de 1995].

CARTA de La Habana [Texto apresentado ao II Congresso de Secretários de Saúde das Américas, Habana, 6 de Junio de 1997].

SOUSA CAMPOS, G.W.; MERHY E.E.; CECILIO, L.C.Q. Inventando a mudança na saúde. São Paulo, HUCITEC, 1994.

JUNQUEIRA, L.A.P. Descentralização e Intersetorialidade: um novo modelo de gestão municipal. Venezuela,1997. [Texto apresentado no II Congresso Interamericando del CLAD, Isla Margarita]

PREFEITURAMUNICIPAL DE FORTALEZA. Lei № 8.000, de 29 de Janeiro de 1997. 
Summary: This work relates the attempt to reach the solutions for the health problems of the population of Fortaleza in the period between the Municipalization of the Public Health Assistance in 1990, and the reform of the City Administration started in 1997. The descentralization and intersectoriality are distinguished as basic fundamentals for building a new pattern wich aims at "Health as means of improvement of quality of life" towards a healthy city.

Key words: Descentralization, Intersectorality, Life Quality, Healthy City 